\title{
RETRACTION: Regression of human metastatic renal cell carcinoma after vaccination with tumor cell-dendritic cell hybrids
}

\author{
Alexander Kugler, Gernot Stuhler, Peter Walden, Gerhard Zöller, AnkeZobywalski, Peter Brossart, Uwe Trefzer, Silke Ullrich, \\ Claudia A. Müller,Volker Becker, Andreas J. Gross, Bernhard Hemmerlein, Lothar Kanz, Gerhard A. Müller \& Rolf-Hermann Ringert \\ Nat. Med. 6, 332-336 (2000)
}

The authors unanimously wish to retract this paper because of several incorrect statements and erroneous presentation of primary data, results and conclusions.

E R R AT U M : Cell-permeable peptides improve cellular uptake and therapeutic gene delivery of replication-deficient viruses in cells and in vivo Jean-Philippe Gratton, Jun Yu, Jason W Griffith, Roger W Babbitt, Ramona S Scotland, Reed Hickey, Frank J Giordano \& William C Sessa Nat. Med.9, 357-362 (2003)

In the "Peptides and viruses" section of the Methods (p. 361), the sequence should have read, “...HIV Tat (amino acids 48-60, GRKKRRQRPPQ) peptides..."

We regret the error.

\section{ER R AT U M : Deletion of cytosolic phospholipase $A_{2}$ promotes striated} muscle growth

Syed Haq, Heiko Kilter, Ashour Michael, Jingzang Tao, Eileen O’Leary, Xio Ming Sun, Brian Walters, Kausik Bhattacharya, Xin Chen, Lei Cui, Michele Andreucci, Anthony Rosenzweig, J Luis Guerrero, Richard Patten, Ronglih Liao, Jeffery Molkentin, Michael Picard, Joseph V Bonventre \& Thomas Force Nat. Med. 9, 944-951 (2003)

In the version of this article initially published online, the last sentence of the 'Isolation of Plag $4 a^{-1-}$ and wild-type glomerular mesangial cells' section of the Methods contained an error. Both instances of ' $\mu \mathrm{m}$ ' should read ' $\mu \mathrm{M}$ '.

We regret the error. 